\title{
HARMONIC SCALPEL POSSIBILITIES IN THE SURGICAL TREATMENT OF SECONDARY HYPERPARATHYROIDISM
}

\author{
Rumen Nenkov, Radoslav Radev, Ekaterina Marinova, Nikolay Cvetkov, Anatoli \\ Semkov, Borislav Petrov \\ Department of Thoracic surgery, UMHAT "St. Marina", \\ Medical University of Varna, Bulgaria.
}

\begin{abstract}
:
The significant changes in coagulation status during chroniodialysis, performed in patients with secondary hyperparathyroidism require completion of meticulous surgical hemostasis in order to prevent active bleeding in the postoperative period.

Aim: To present our experience with harmonic scalpel application in the surgical treatment of secondary hyperparathyroidism.

Patients and Methods: 112 patients with secondary hyperparathyroidism (77 males and 35 females, aged from 23 to 60 years) have been operated on in our institution for 10 years period. All patients were on chroniodialysis. Hemostasis was achieved using conventional instruments and electrocautery in 46 patients and in 66 patients harmonic scalpel of Ethicon EndoSurgeryCare has been used. All patients had serum levels of parathormone above $2500 \mathrm{ng} / \mathrm{l}$. Ultrasonic examination revealed at least 2 parathyroid glands larger than $10 \mathrm{~mm}$ in all cases. The amount of blood loss, necessity and type of drainages used, frequency of postoperative complications, postoperative hospital stay were comparatively evaluated.

Results: In 12 patients parathyroidectomy with autotransplantation was carried out, in 62 patients subtotal parathyroidectomy was performed. In the rest 35 casesthree of the parathyroid glands were removed (because of the impossibility to identify the fourth parathyroid gland, using ultrasonic and intraoperative methods). All patients were proven to have a sharp decrease in parathormone and Calcium serum levels. In the group of patients, where conventional instruments and electrocautery for hemostasis have been used, corrugated and tube drainages were applied as a rule. For the patients, in whom hemostasis was performed using a harmonic scalpel, simple glove drainages were used. In all patients in the preoperative and post-operative period serial hemodialysis was done with LMW heparin administration. Significantly lower blood loss from the surgical wound was found in
\end{abstract}

the group, where harmonic scission was used.

Conclusions: We consider that the application of harmonic scalpel in the surgical treatment of patients with secondary hyperparathyroidism on chroniodialysis leads to safer hemostasis, lower postoperative complications rate and thus shortens the postoperative hospital stay.

Key words: secondary hyperparathyroidism, harmonic scalpel, surgery, autotransplantation.

The secondary hyperparathyroidism (SHPT) is a common complication in patients with chronic renal failure. Around $40 \%$ of patients on chroniodialysis, after a 15 years period undergo parathyroidectomy ${ }^{1}$. During the last 30 years several surgical strategies for the treatment of SHPT were developed: subtotal parathyroidectomy was first published by Stanbury et al. in 1960 [2], total parathyroidectomy by Ogg in 1967 [3] and total parathyroidectomy with autotransplantation by Geis et al. in 1973 [4].

The surgical treatment requires completion of meticulous surgical hemostasis in order to prevent active bleeding as a consequence of the changes in coagulation status during dialysis. This paper aims to present the experience of our institution with harmonic scalpel application in the surgical treatment of SHPT.

\section{PATIENTS AND METHODS}

For a 10 years period 112 patients with secondary hyperparathyroidism ( 77 males and 35 females, aged from 23 to 60 years) underwent surgery in our clinic. All patients have been on chroniodialysis since one to fifteen years before the procedure.

In 46 patients the surgical treatment and hemostasis were performed using conventional equipment and in $66-$ using harmonic scalpel (Ethicon EndoSurgery Care)/Fig. $1 /$ : 

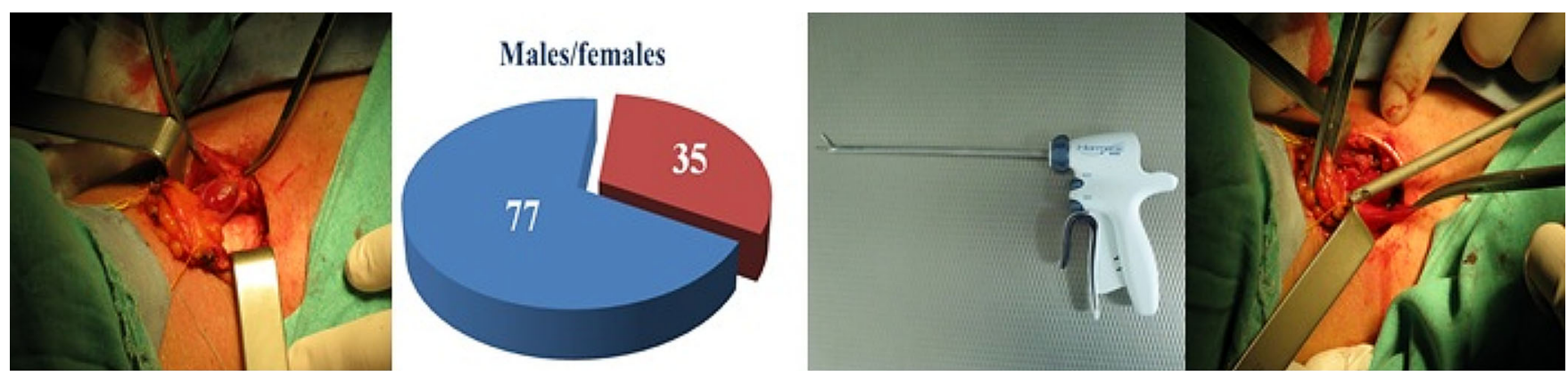

Fig. 1. Distribution of patients with hyperparathyroidism operated on with conventional instruments and with harmonic scalpel.

All patients had serum levels of parathormone above $2500 \mathrm{ng} / \mathrm{L}$. Ultrasonography revealed at least two parathyroid glands, above $10 \mathrm{~mm}$ in size.

Comparative assessment of intraoperative blood loss, quality of achieved hemostasis, necessity and type of used drainages, rate of postoperative complications and length of postoperative hospital stay has been made.

\section{RESULTS}

In 77 patients 4 to 6 hyperplastic parathyroid glands have been detected, from 7 to $25 \mathrm{~mm}$ in size /Fig. 2/.

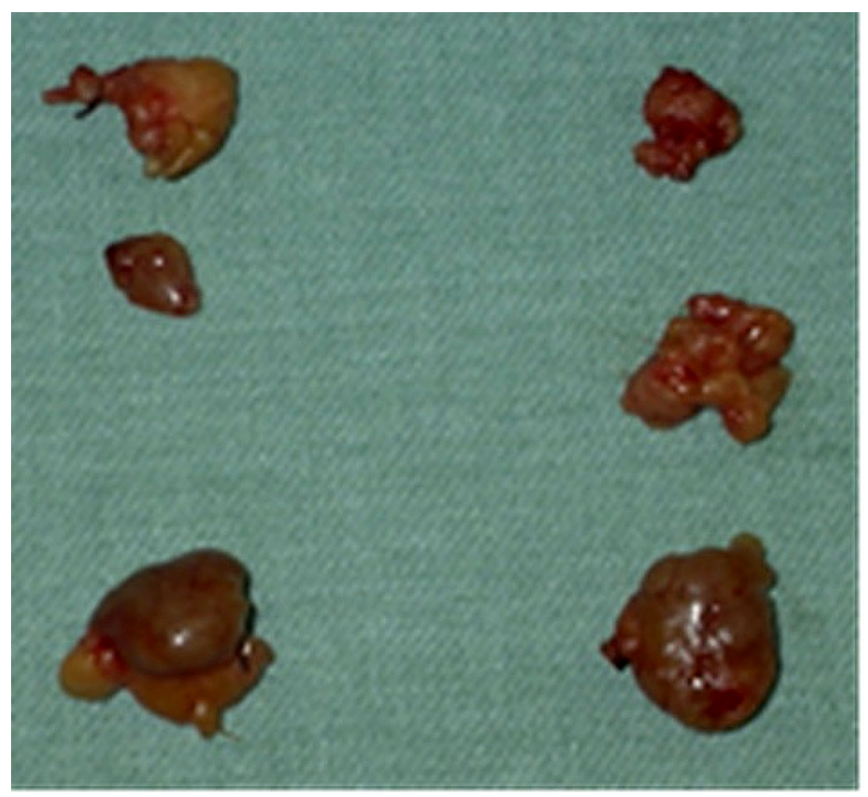

Fig. 2. Number of detected parathyroid glands.

In 15 patients parathyroidectomy with autotransplantation was performed /Fig. 3/.

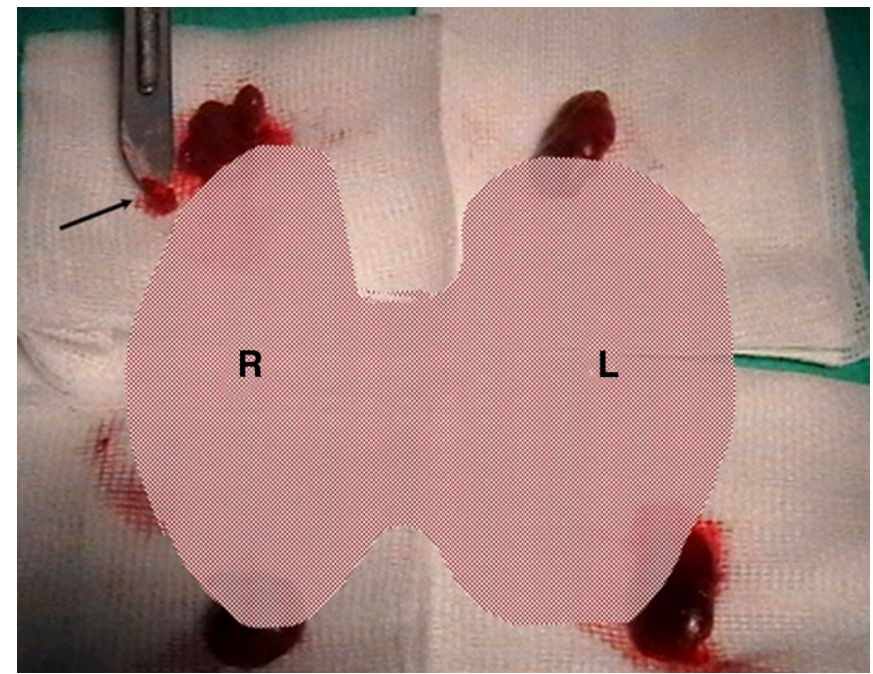

Fig. 3. Parathyroidectomy with prepared for autotransplantation part of right upper parathyroid gland / arrow/.

Subtotal parathyroidectomy was performed in 62 patients /Fig. 4/.

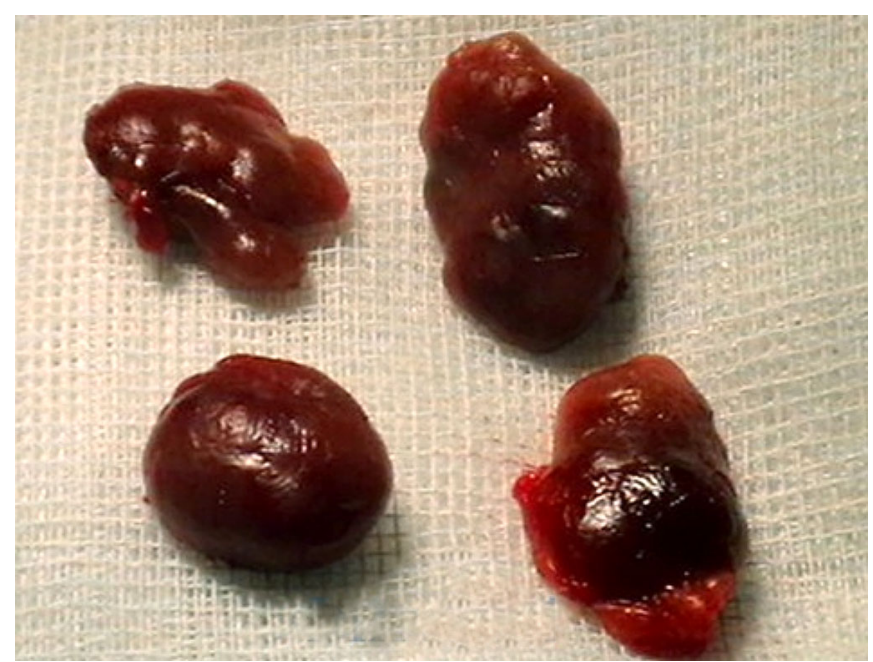

Fig. 4. Subtotal parathyroidectomy. 
In the remaining 35 cases three parathyroid glands have been removed because of inability to identify the fourth parathyroid during the diagnostic evaluation or intraoperatively (Table 1).

Table 1. Extent of surgical intervention using conventional equipment and harmonic scalpel.

\begin{tabular}{|l|c|c|c|}
\hline & PARATHYROIDECTOMY & $\begin{array}{c}\text { SUBTOTAL } \\
\text { PARATHYROIDECTOMY }\end{array}$ & $\begin{array}{c}\text { REMOVAL OF THREE } \\
\text { PARATHYROID GLANDS }\end{array}$ \\
\hline $\begin{array}{l}\text { WITH CONVENTIONAL } \\
\text { EQUIPMENT }\end{array}$ & 4 & 27 & 15 \\
\hline $\begin{array}{l}\text { WITH HARMONIC } \\
\text { SCALPEL }\end{array}$ & 11 & 35 & 20 \\
\hline
\end{tabular}

In the patients group where conventional instruments and electrocautery have been used, the degree of hemostasis was worse, which lead to the need from corrugated or tubular drainages, usually removed after the second postoperative dialysis. In the group with harmonic scalpel use, the intraoperative hemostasis is much better and there was no need for vessel ligatures and the procedure finished as a rule with insertion of gloves drainages. The bleeding

established after the first postop dialysis was significantly larger in the group with conventional instruments and electrocautery. The monitoring of serum levels of parathormone and calcium on the $24^{\text {th }}$ hour demonstrated sharp decrease in their values.

The discharge from the hospital in the group with conventional instruments and electrocautery was not earlier than after the second postoperative dialysis and in the harmonic scalpel group it occurred earlier - after the first postoperative dialysis.

\section{DISCUSSION}

Secondary hyperparathyroidism is a mineral homeostasis disturbance predominantly in patients with chronic renal diseases $[5,6,7]$. As a consequence of the renal failure, retention of phosphates, vitamin D deficiency and hypocalcaemia occur, leading to pathological increase in parathormone secretion [7].

The pathogenesis of this parathyroid disease is not sill completely clear. In the earlier stage of the disease a polyclonal hyperplasia of parathyroid cells is usually found. For later stages of secondary hyperparathyroidism neoplastic transformation of preexisting polyclonal hyperplasia to monoclonal zones is typical which probably plays leading role in the course of the disease.

Total parathyroidectomy is recommended in patients with hyperparathyroidism refractory to medical treatment [5, 8].

The indications to perform parathyroidectomy are still not well defined. There is a lack of studies, which could undoubtedly point the biochemical markers of lack of efficiency from the medicated treatment and requiring surgical intervention to control the hyperparathyroidism. Classic indication for surgical parathyroidectomy is the medication treatment resistant hypercalcemia and hyperphosphatemia in combination with severe hyperparathyroidism (erum level of PTH 8 fold above the normal range). The severe hypercalcemia with PTH above $55 \mathrm{pmol} / \mathrm{l}$ is still considered an absolute indication for parathyroidectomy $[9,10]$.

The objectives of the surgical treatment of secondary hyperparathyroidism are to eliminate the symptoms of PTH overproduction, meanwhile escaping the postoperative hypocalcemia as a result of the lack of parathyroid tissue.

Preservation of adequate volume remnant parathyroid tissue $(0,5 \times 0,5 \times 0,5 \mathrm{~cm}$ tissue or $60-100 \mathrm{mg})$ is of crucial importance [11].

Two main surgical techniques are in use: Subtotal parathyroidectomy and total parathyroidectomy with autotransplantation.

The total parathyroidectomy without autotransplantation would result in a complete deficiency of parathormone, which requires lifelong substitution with calcium and vitamin D and may have significant impact on the bone mineralization. That is the reason for this technique has been abandoned by most of the surgeons [5].

To reach the posterior surface of the thyroid gland where the parathyroids are located, particularly precise and bloodless dissection is necessary, in the situation of impaired coagulation status.

The success of the surgical treatment depends exceptionally on: 1) the successful identification of all parathyroid glands and 2) the possibility to leave an optimal amount of remnant parathyroid tissue.

Leaving parathyroid remnants in an exceeding or insufficient amount may lead to serious complications or recurrence of the SPTH [1]. Maximal success in the 
parathyroid glands identification is achieved with the intraoperative use of radio-guided probe [6].

The harmonic scalpel use permits to perform all procedures after the initial skin incision, including tissue lamination, dissection and hemostasis with adequate precision and without bleeding. The extirpation of the parathyroid glands after theirs localization is also performed using the harmonic scalpel. Only in the performance of subtotal parathyroidectomy, when an amount of $60 \mathrm{mg}$ parathyroid remnant from the smallest parathyroid gland must be leaved, we use fine instruments to avoid necrosis in the remnant tissue if harmonic scalpel has been used.

The hemostasis achieved with harmonic scalpel use is better and there was not bleeding during the next dialysis in contrast to the patients where conventional instruments and ligatures have been used. The latter cases require mandatory use of corrugated or tube drainages, as well as prolonged hospital stay for this patients group.

In the available literature we did not found any report concerning the harmonic scalpel use in the surgical treatment of the secondary hyperparathyroidism. The observations from our practice about the good quality of hemostasis with harmonic scalpel use, as well as the lack of complications, gives us the reason to propose this technique as a routine in the surgical treatment of secondary hyperparathyroidism.

\section{CONCLUSIONS}

We consider the harmonic scalpel application in the surgical treatment of patients with secondary hyperparathyroidism and on chroniodialysis leads to better and secure hemostasis, reduced postoperative complications rate and shortened postoperative hospital stay.

\section{REFERENCES:}

1. Fassbinder W, Brunner FP, Brynger H, Ehrich JH, Geerlings W, Raine AE, et al. Combined report on regular dialysis and transplantation in Europe. XX, 1989. Nephrol Dial Transplant. 1991; 6(Suppl 1):5 -35. [PubMed]

2. Stanbury SW, Lumb GA, Nicholson WF. Elective subtotal parathyroidectomy for renal hyperparathyroidism. Lancet. 1960 Apr 9; 1(7128):793-799. [PubMed]

3. Ogg CS. Total parathyroidectomy in treatment of secondary (renal) hyperparathyroidism. Br Med J. 1967 Nov 11;4(5575):331-334. [PubMed]

4. Geis WP, Popovtzer MM, Corman JL, Halgrimson CG, Groth CG, Starzi TE. The diagnosis and treatment of hyperparathyroidism after renal homotransplantation. Surg Gynecol Obstet 1973 Dec;137(6):997-1010. [PubMed]

5. Daniel Oertli, Robert Udelsman. Surgery of the Thyroid and Parathyroid Glands. Springer-Verlag Berlin Heidelberg. 2007. [CrossRef]

6. Ogi S, Fukumitsu N, Uchiyama M, Mori Y, Takeyama H. The usefulness of radio-guided surgery, in secondary hyperparathyroidism, Ann Nucl Med. 2004 Feb;18(1):69-71. [PubMed]

7. Silver J, Kilav R, Naveh-Many T. Mechanisms of secondary hyperparathyroidism, Am J Physiol Renal Physiol 2002 Sep;283(3):F367-76. [PubMed]

8. Leapman SB, Filo RS, Thomalla JV, King D. Secondary hyperparathyroidism. The role of surgery. Am
Surg. 1989 Jun;55(6):359-65. [PubMed]

9. Jorge Cannata-Andia JP-DER (2000) Management of the renal patient: experts' recommendations and clinical algorithms on renal osteodystrophy and cardiovascular risk factors. Nephrol Dial Transplant 15:S1-S154. [CrossRef]

10. National Kidney Foundation. K/ DOQI clinical practice guidelines for bone metabolism and disease in chronic kidney disease. Am J Kidney Dis. 2003 Oct;42(4 Suppl 3):S1-201. [PubMed]

11. Chou FF, Lee $\mathrm{CH}$, Chen HY, Chen JB, Hsu KT, Sheen-Chen SM. Persistent and recurrent hyperparathyroidism after total parathyroidectomy with autotransplantation. Ann Surg. 2002 Jan;235(1):99104. [PubMed]

\author{
Address for correspondence: \\ Rumen Nenkov M.D., PhD \\ Clinic of Thoracic Surgery, UMHAT "St. Marina”, Varna \\ Medical University "Prof. Paraskev Stoyanov", Varna \\ 1, Hristo Smirnenski str., Varna, Bulgaria \\ E-mail: nenkovrn@hotmail.com;
}

http://www.journal-imab-bg.org 